\title{
How to approach castration-resistant prostate cancer?
}

\author{
Sevil BAVBEK
}

\begin{abstract}
The therapeutic landscape of castration-resistant prostate cancer (CRPC) has changed dramatically in the last decade. Previously, limited to castration, second-line hormonal manipulations, and palliative treatment with mitoxantrone plus prednisone, median overall survival (OS) remained in the 9-18 months range. With multiple lines of survival improving chemotherapies, AR-directed drugs, as well as new immunotherapy and bone-directed therapies, median OS increased to more than 30 months and quality of life increased accordingly. The question remains, as how to sequence, and choose the best therapeutic option for each individual patient with the current data.
\end{abstract}

Keywords: Prostatic neoplasms, Castration-resistant, Immunotherapy, Chemotherapy, Antineoplastic agents, Hormonal, Radioimmunotherapy

\section{Introduction}

Androgen deprivation is the backbone of therapy for advanced prostate cancer, and this treatment leads to response in terms of both prostate-specific antigen (PSA) responses and clinical improvements in the great majority of patients [1]; however, this treatment is not curative and the most patients eventually progress to become castration resistant. The term 'hormone-resistance' is not used

Sevil Bavbek, M.D.,(区)

VKV American Hospital, Istanbul, Turkey

sbavbek@yahoo.com anymore, since the androgen receptor (AR) still remains an important pathway for growth during the castration resistant period. Castration-resistant prostate cancer (CRPC) is used to describe a heterogeneous group of patients including those with/without metastases or symptoms. The Prostate Cancer Working Group 2 (PCWG2) defines CRPC as prostate cancer progressing despite castrate levels of testosterone $(<0.5 \mathrm{ng} /$ $\mathrm{ml}$ ); this progression may be biochemical (PSA progression only), radiological or symptomatic [2].

The therapeutic landscape of CRPC has changed dramatically in the last decade. Previously limited to castration, second-line hormonal manipulations, and palliative treatment with mitoxantrone plus prednisone, median overall survival (OS) remained in the 9-18 months range. With multiple lines of survival improving chemotherapies, AR-directed drugs, as well as new immunotherapy and bone-directed therapies, median OS increased to more than 30 months and quality of life increased accordingly [3]. Improvement came in small but consistent steps at first and quite giants leaps later on, with zoledronic acid leading the initial improvement wave with reduction of skeletal-related event (SRE) incidence [4]. The TAX 327 study followed in 2004, demonstrating improved OS with docetaxel [5]. The SWOG 9916 trial confirmed the efficacy of docetaxel, accompanied by extramustine [6]. In 2010, immunotherapy with sipuleucel-T was approved by the US FDA due to prolonged survival in non-metastatic or minimally metastatic PSA progressing patients [7]. Cabazitaxel, a novel tubulin-binding taxane, followed in 2011, demonstrating efficacy as second-line chemotherapy after docetaxel [8], and denosumab significantly prolonged the median time to the first SRE [9]. Between 2011 and 2012, AR-directed agents, abiraterone acetate and enzalutamide, showed further OS improvements in the post-docetaxel 
setting [10,11]. In 2013, radium-223, an $\alpha$-emitting radium isotope, was announced to improve survival in the postdocetaxel setting, in those patients with predominant bone metastases [12] as well as delaying time to symptomatic skeletal events (SSE). Effective therapies are listed in Table I. The question remains, as how to sequence, and choose the best therapeutic option for each individual patient with the current data.

Table I. Approved therapies for the treatment of metastatic castration-resistant prostate cancer

\begin{tabular}{|c|c|c|}
\hline Drug & Target & Effect \\
\hline $\begin{array}{l}\text { Abiraterone } \\
\text { acetate }\end{array}$ & CYP17A1 & $\begin{array}{l}\text { Reduces circulating } \\
\text { testosterone levels }\end{array}$ \\
\hline Cabazitaxel & Microtubules & $\begin{array}{l}\text { Microtubule stabilization, } \\
\text { interrupts cell cycle }\end{array}$ \\
\hline Denosumab & RANKL & $\begin{array}{l}\text { Decreases bone resorp- } \\
\text { tion }\end{array}$ \\
\hline Docetaxel & Microtubules & $\begin{array}{l}\text { Microtubule stabilization, } \\
\text { interrupts cell cycle }\end{array}$ \\
\hline Enzalutamide & $\mathrm{AR}$ & $\begin{array}{l}\text { AR receptor antagonism, } \\
\text { prevents signaling }\end{array}$ \\
\hline Radium-223 & Bone & Localized radiation \\
\hline Sipuleucel-T & $\begin{array}{l}\text { Ex vivo activation of } \\
\text { PBMC's via GM-CSF } \\
\text { and PAP }\end{array}$ & T-cell activation \\
\hline Zoledronic acid & Osteoclasts & $\begin{array}{l}\text { Decreases bone } \\
\text { resorption }\end{array}$ \\
\hline
\end{tabular}

\section{AR-DIRECTED TREATMENT}

Huggins originally described the therapeutic role of castration in prostate cancer [13]. Intraprostatic androgen levels were found to remain significantly higher despite the dramatic reduction of serum testosterone, indicating that progression is not always due to true androgen independence, but rather to functional adaptation that results in continuous AR-mediated signaling despite low levels of circulating androgens [14]. Mechanisms, including AR gene mutations [15], AR splice variant expressions [16], AR gene overexpression [17], increased expression of proteins acting as transcriptional co-activators [15], TMPRSS2/ERG fusion, $P T E N, N k x 3.1$, and EGRl overexpression, and up-regulation of the enzymes involved in androgen synthesis, namely CYP17 $\alpha$-hydroxylase and C17-20-lyase (CYP17) [18]. Therefore, despite castration levels of androgen, in CRPC, the AR signaling pathway remains active. Mechanisms of castration resistance are depicted in Figure 1. Consequently, new agents have been developed in order to interfere with the AR pathway or to inhibit CYP17 in order to potently block androgen synthesis.

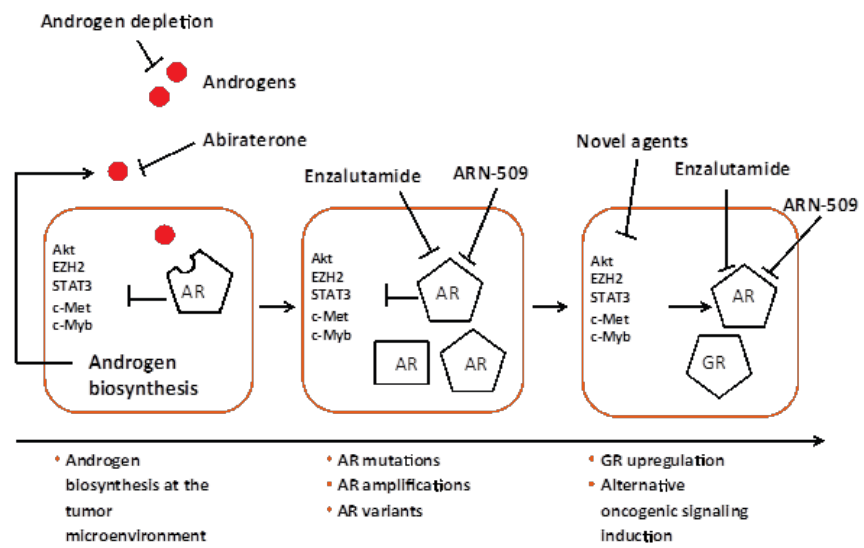

Figure 1. Mechanisms of Castration Resistance [14]

\section{Abiraterone}

Abiraterone is a steroidal agent that selectively and irreversibly inhibits the CYP17A1 microsomal enzyme, encoded by the CYP17A1 gene, which has two distinct activating properties: one is its $17-\alpha$-hydroxylase property, which catalyzes the 17- $\alpha$-hydroxylation of C21 steroids that are necessary for the synthesis of cortisol in the adrenal gland [19] and the other is its 17,20-lyase property, which catalyzes the scission of the $\mathrm{C} 17-21$ bond, converting $\mathrm{C} 21$ compounds to $\mathrm{C} 19$ steroids in the sex steroid synthesis pathway in the both adrenal gland and the testis [20].

Inhibition of CYP17 results in cortisol deficiency and consequent upregulation of the hypothalamic-pituitaryadrenal pathway with elevated levels of adrenocorticotropic hormone. Elevated ACTH generates a syndrome of secondary mineralocorticoid excess characterized by fluid retention, hypertension and hypokalemia, which often require intervention. In order to prevent this side effect, abiraterone is usually administered together with prednisone [21].

Initial phase II trials demonstrating the efficacy of abiraterone after docetaxel was followed by a large, randomized, double-blind Phase III trial (COU-AA-301), which, using a 2:1 randomization, 1195 docetaxel-refractory CRPC patients received either abiraterone $1 \mathrm{~g}$ /daily or placebo; both arms received prednisone $5 \mathrm{mg}$ twice daily. 
The study was unblinded at the time of the first interim analysis because of an OS improvement of 3.9 months favoring abiraterone (14.8 vs. 10.9 months; hazard ratio [HR]: 0.646; 95\% CI: 0.54-0.77; p < 0.001)-[10]. An updated OS analysis conducted before crossover showed a median OS improvement of 4.6 months (HR: $0.74 ; 95 \%$ CI: $0.64-0.86 ; p<0.0001$ ) [22]. Abiraterone also improved time to PSA progression (8.5 vs. 6.6 months; $\mathrm{p}<0.0001$ ), radiographic PFS (rPFS; 5.6 vs. 3.6 months; $\mathrm{p}<0.0001$ ), with $50 \%$ PSA declines (confirmed: 29.5 vs. $5.5 \%$; p $<$ 0.0001 ) [22]. Survival improvement was consistent across all age groups, prior number of chemotherapy regimens, type of progression (PSA vs. radiographic), the absence or presence of pain. Benefit was marginal in patients with visceral metastases, and performance status $\geq 2$. Mineralocorticoidrelated adverse events, including fluid retention $(31 \%$ vs. $22 \%$ placebo; $\mathrm{P}<0.001)$ and hypokalemia $(17 \%$ vs. $8 \%$ placebo), were more frequently reported in the Abiraterone acetate-prednisone group than in the placebo-prednisone group. There was a non-significant increase in grade 1-2 cardiac events in the treatment group (13\% vs. $11 \%$ placebo). Abiraterone acetate is now considered standard of care for patients following chemotherapy.

A large phase III trial (COU-AA-302) randomized almost 1000 patients with asymptomatic or minimally symptomatic CRPC in the pre-chemotherapy setting, to either abiraterone and prednisone or prednisone alone; the primary end points were rPFS and OS [23]. Abiraterone significantly improved rPFS (16.5 vs. 8.2 months; HR: 0.52 ; $95 \%$ CI: $0.45-0.61$; $\mathrm{p}<0.0001)$. It also showed a trend towards improved OS (median not reached, vs. 27.2 months for prednisone alone; HR 0.75 ; 95\% CI, 0.61 to $0.93 ; \mathrm{P}=0.01$ ). Abirateroneprednisone showed superiority over prednisone alone with respect to time to initiation of cytotoxic chemotherapy (25.2 vs. 16.8 months, p-value $<0.001)$ opiate use for cancerrelated pain (not reached vs. 23.7 months, p-value $<0.001$ ), prostate-specific antigen progression (11.1 vs. 5.6 months, p-value $<0.001$ ), and decline in performance status (12.3 vs. 10.9 months, p-value 0.005) [23, 24]. Based on these data, the FDA and EMA approved abiraterone for the management of both docetaxel-naive and docetaxel pre-treated patients.

Toxicity profile: The main adverse events of Abiraterone are related to excess mineralocorticoid, which includes fluid retention (33\%) and hypokalemia (18\%). This is due to the inhibition of 17 alpha hydroxylase, which causes a compensatory rise in ACTH. Abiraterone should be administered with prednisone daily and monthly potassium and blood pressure monitoring is essential during treatment. While co-administration of prednisone is manageable, longterm use in earlier disease phases could be problematic due to the potential adverse events. These include diabetes, weight gain, Cushing syndrome and osteoporosis. Fatigue, joint swelling, edema, cough, vomiting, elevated liver enzymes, hyperglycemia and hypercholesterolemia have also been reported.

In a recent retrospective study, Peer et al. found abiraterone to be superior to ketoconazole in the treatment of docetaxel refractory mCRPC. PSA response was $46 \%$ in the abiraterone group vs. $19 \%$ in the ketoconazole group (OR 4.3, $\mathrm{P}=0.04$ ), median biochemical progression free survival (PFS) 7 vs. 2 months (HR 1.54, $\mathrm{P}=0.02$ ), median radiological PFS 8 vs. 2.5 months (HR 1.8, $\mathrm{P}=0.043$ ), median OS 19 vs. 11 months (HR $0.53, \mathrm{P}=0.79)$ and treatment interruption due to severe adverse events $8 \%(n=2)$ versus $31 \%(n=8)(0 R 0.6, P=0.023)$.

\section{Orteronel}

Orteronel (TAK-700) is a CYP17 inhibitor with relative selectivity for 17,20-lyase over 17- $\alpha$-hydroxylase. This selectivity improves the drug safety profile when compared with agents inhibiting both enzymes in testosterone synthesis. TAK-700 has fewer mineralocorticoid effects than abiraterone, omitting the need for prednisone, and making orteronel an attractive drug for long-term therapy. Phase I/II trials, TAK700 showed promising results at $300-400 \mathrm{mg}$ twice daily [25]. Two ongoing randomized, placebo-controlled Phase III trials are evaluating orteronel in patients with progressive CRPC who are either chemotherapy naive (NCT01193244) or pretreated with docetaxel (NCT01193257). The postdocetaxel trial was recently unblinded and terminated at the interim analysis because orteronel plus prednisone did not meet the primary end point of improved OS when compared with placebo (HR: 0.886; p = 0.1898) [26]. Orteronel, however, did provide a benefit in radiographic progression free survival rates in both chemotherapy naive and postchemotherapy mCRPC $[26,27]$.

\section{Enzalutamide (Xtandi ${ }^{\circledR}$ )}

Enzalutamide (formerly MDV300) is an oral, secondgeneration androgen receptor antagonist that competitively inhibits androgen binding to the AR. In contrast to the first generation anti-androgens such as flutamide and bicalutamide, enzalutamide binds to the receptor with greater affinity. Enzalutamide may induce a conformational change in AR distinct from that induced by bicalutamide making it more efficacious in inhibiting the translocation of AR to the nucleus and its DNA interaction. In a phase I-II study, 140 men including 78\% with mCRPC received doses ranging from $30-600 \mathrm{mg}$ daily. PSA responses were observed in $62 \%$ of the chemotherapy naïve patients and $51 \%$ in docetaxel treated patients [29]. $22 \%$ of the patients 
had a soft tissue response and $56 \%$ of the patients with bone disease had stabilized bone disease. The maximum tolerated dose was determined to be $240 \mathrm{mg}$ daily. The median rPFS was 56 weeks and 24 weeks in the chemotherapy naïve and the chemotherapy pretreated group, respectively.

Enzalutamide was approved after the publication of a phase III, double-blind placebo-controlled randomized trial by Scher et el (AFFIRM TRIAL) in which 1199 men with mCRPC were randomized after chemotherapy to placebo vs. oral enzalutamide at a dose of $160 \mathrm{mg}$ per day [30]. The median OS was 18.4 months in the enzalutamide group versus 13.6 months in the placebo group $(\mathrm{P}<0.001)$. The secondary endpoints including the PSA- level response rate $(54 \%$ vs. $2 \%$ ), soft tissue response rate ( $29 \%$ vs. $4 \%$ ), the time to PSA progression ( 8.3 vs. 3 months), rPFS ( 8.3 vs. 2.9 months), time to the first skeletal event (16.7 vs. 13.3 months), quality of life response rate ( $43 \%$ vs. $18 \%$ ), pain palliation achieved in $(45 \%$ vs. $7 \%$ ) showed significant improvement in the enzalutamide group. The enzalutamide group had higher incidence of fatigue, hot flashes, musculoskeletal pain and headaches. Hypertension was seen in $6.6 \%$ in the enzalutamide group vs. $3.3 \%$ in the placebo group. Seizures were reported in $0.6 \%$ in the enzalutamide group vs. placebo.

The results of the large phase III randomized trial (PREVAIL trial) were recently presented at the 2014 Genitourinary Cancer Symposium [31]. In the PREVAIL study, 1,717 chemotherapy naïve patients with mCRPC were assigned to receive $160 \mathrm{mg}$ /day of enzalutamide vs. placebo in a double blind fashion. After a median followup of 20 months, interim analysis showed that enzalutamide significantly reduced the risk of death by $29 \%$ (HR 0.706 , 95\% CI $0.60-0.84, \mathrm{p}<0.0001)$ and decreased the risk of radiographic progression by $81 \%$ (HR $0.186,95 \%$ CI $0.15-$ $0.23, \mathrm{P}<0.0001$ ). $59 \%$ of the patients in the enzalutamide group had a soft tissue response compared with $5 \%$ in the placebo arm. Enzalutamide also delayed the median time to chemotherapy initiation by 17 months as compared to placebo. The patients on the placebo arm needed to start cytotoxic chemotherapy after a median of 10.8 months due to disease progression. Median time to PSA progression was 2.8 months in the placebo group vs. 11.2 months in the enzalutamide group. The adverse effects included grade $1-2$ fatigue ( $36 \%$ vs. $26 \%$ ), back pain ( $27 \%$ vs. $22 \%$ ) constipation ( $22 \%$ vs. $17 \%)$ and arthralgia (20\% vs. $16 \%)$ in the enzalutamide vs. placebo group. The patients with a history of seizure disorders were excluded from the trial.

Enzalutamide has been approved by the FDA for the treatment of CRPC both before and after docetaxel.

Toxicity profile: Enzalutamide is reported to cause fatigue $(11 \%)$, hot flashes $(20 \%)$, headache $(12 \%)$, nausea, diarrhea, constipation and musculoskeletal pain. Other reported adverse events include hyperglycemia, weight gain and glucose intolerance. Seizure was reported in $0.6 \%$ of the enzalutamide group at 360 to $600 \mathrm{mg}$ doses. Thus, the maximum tolerated dose (MTD) is $240 \mathrm{mg} /$ day.

Galeterone (TOK-001) works by disrupting multiple androgen signaling pathways simultaneously and by down regulating the androgen receptor [32]. ARMOR 1 was a multicenter dose escalation study of Galeterone for the treatment of chemotherapy naïve non-metastatic prostate cancer and mCRPC [33]. The data from ARMOR 1 were presented at the 2012 AACR and 2012 ASCO meetings, showed that the drug is well tolerated. ARMOR2 is an ongoing phase II multicenter trial to evaluate the efficacy and safety of Galeterone in the following populations metastatic treatment naïve patients, non-metastatic treatment naïve patients, patients who have progressed on Abiraterone and patients who have progressed on Enzalutamide. The primary endpoints of the study are reduction in PSA levels and safety. The secondary endpoints include tumor response by the Response Evaluation Criteria in Solid Tumors (RECIST), AR modulation and levels of circulating tumor cells and markers of CYP17lyase inhibition [34].

ARN509 is a small molecule that is structurally similar to enzalutamide. It inhibits both AR nuclear translocation and AR binding to DNA [34]. In contrast to bicalutamide, it exhibits no agonist activity in prostate cancer cells that over express AR. In a preliminary study, among 46 men with mCRPC, 26 were treatment naïve and 21 had prior treatment with abiraterone. At 12 weeks, the PSA response was $88 \%$ in the treatment naïve and $29 \%$ in the prior-treatment group [35]. The toxicity profile included fatigue $(38 \%)$, nausea (29\%) and pain (24\%). Currently, a phase II multicenter study (NCT01171898) is evaluating the activity of ARN509 in three different populations of men with mCRPC (high risk non-metastatic CRPC, metastatic treatment naïve CRPC and progressive disease after abiraterone acetate) and further phase III trials are planned.

\section{CHEMOTHERAPY in CRPC}

\section{Taxanes}

Taxanes bind to different sites on the intracellular $\beta$-tubulin subunit of microtubules and promote tubulin assembly into microtubules. These microtubule bundles act in the mitotic phase of the cell cycle and impair the natural dynamics of microtubules, leading the cancer cell to mitotic block and apoptosis. Furthermore, the suppression of microtubule dynamics enhances p53 nuclear accumulation, thereby promoting the activation of the p53 downstream target genes. 
Several preclinical studies suggest that taxanes also have anti-angiogenic effects, and inhibit the nuclear accumulation of AR, as its trafficking is microtubule dependent. Therefore, taxanes may have AR-directed effect on CRPC as well as cytotoxic efficacy.

\section{Docetaxel}

The TAX 327 study was the first to show a survival benefit with chemotherapy in CRPC. In the study, 1006 patients with CRPC were randomized to three-arms, in order to compare two dose schedules of docetaxel $\left(75 \mathrm{mg} / \mathrm{m}^{2}\right.$ every 3 weeks or $30 \mathrm{mg} / \mathrm{m}^{2}$ weekly for 5 of every 6 weeks) plus prednisone versus mitoxantrone $12 \mathrm{mg} / \mathrm{m}^{2}$ every 3 weeks plus prednisone. The median OS with docetaxel every 3 weeks was 19.2 months, compared with 16.3 months for patients in the control arm $(\mathrm{p}<0.004)$. Weekly docetaxel did not result in a significant survival benefit (17.8 months) [37]. Treatment was also associated with significant improvement in pain and PSA decline. There were no significant differences between the two docetaxel arms in terms of response rates. The most common toxicity neutropenia, occurred more frequently in the every-3-week docetaxel regimen vs. mitoxantrone (32 vs. $22 \%$; $p<0.005$ ) [5].

The SWOG 99-16 trial acted as a confirmatory trial, randomizing 770 patients to docetaxel $60 \mathrm{mg} / \mathrm{m}^{2}$ every 3 weeks plus estramustine $280 \mathrm{mg}$ orally three-times daily on days $1-5$ or mitoxantrone $12 \mathrm{mg} / \mathrm{m}^{2}$ every 3 weeks plus prednisone $5 \mathrm{mg}$ orally twice daily continuously. The docetaxel and estramustine had a significant improvement in median OS (17.5 vs. 15.6 months; $p=0.02$ ), longer PFS (6 vs. 3 months; $p<0.001$ ) and superior median PSA declines [6].

Based on the survival benefit observed in the TAX 327 trial, the FDA and EMA granted approval for docetaxel 75 $\mathrm{mg} / \mathrm{m}^{2}$ every 3 weeks in combination with prednisone as a front-line therapy for $\mathrm{mCRPC}$.

Docetaxel re-challenge has never been tested in a phase 3 trial and lacks survival benefit data. The clinical benefit data is mostly retrospective. In a Phase II clinical trial in a group of pretreated patients with CRPC, it was demonstrated that docetaxel retreatment preserves antitumor activity and is well tolerated [38]. Docetaxel re-challenge, once popular in the era of no treatments with demonstrated survival benefit, must be considered carefully today, for fear of delaying effective treatment choices.

The clinical setting of pre-docetaxel and post-docetaxel treatments were designated to introduce new drugs into the armamentarium of CRPC, acquire approval and reimbursement. This clinical classification has recently been further disrupted by the announcement of the groundbreaking results of the CHAARTED trial (ECOG E3805) [39]. For patients with metastatic hormone-sensitive prostate cancer, upfront chemotherapy with docetaxel, given at the same time as hormone therapy at diagnosis instead of later, prolongs survival. This finding has been described as "practice-changing" and "transformative". The study evaluated 790 men with metastatic hormone-sensitive prostate cancer who received androgen-deprivation therapy (ADT). Of this cohort, 397 were randomized within 4 months of starting ADT to receive docetaxel $75 \mathrm{mg} / \mathrm{m}^{2}$ every 3 weeks for 6 cycles. In accordance with the current standard of care, the 129 patients who progressed on ADT alone were eventually given docetaxel, thus providing crossover to the treatment arm. Preliminary results showed fewer deaths with ADT plus docetaxel than with ADT alone (104 vs. 137), and median OS was longer with the combination (57.6 vs. 44.0 months; hazard ratio [HR], 0.47; $P=.0003$ ) [39]. The number of patients who had a significant and major suppression of their PSA level was doubled with the combination. Median time to progression - an elevation in PSA level, new symptoms, or worsening scans - was significantly longer with the combination than with ADT alone (20.7 vs. 14.7 months; $P<.001$ ), as was median time to the harder end point of clinical progression (32.7 vs. 19.8 months; $P<.001)$.

The combination, compared with ADT alone, was particularly effective in the 520 men with high-volume disease, where the increase in survival was 17 months (median overall survival, 49.2 vs. to 32.2 months; HR, $0.60 ; P=.0006)$. Benefit has not yet been observed in the low volume disease group since they have not reached the median survival yet, but there is a similar trend observed.

The upfront use of docetaxel in non-CRPC metastatic disease is expected to cause a major change in treatment algorithm and treatment sequencing, raising new questions to be answered through randomized trials.

\section{Cabazitaxel}

Resistance to taxanes is primarily associated with increased expression of the MDR1 gene that encodes P-glycoprotein, an ATP-dependent drug efflux pump that decreases the intracellular concentration of these drugs. Cabazitaxel is a 7,10-dimethyloxy derivative of docetaxel [40] and, due to the presence of these extra methyl groups, is effective in docetaxel-resistant tumors because of a poor affinity for P-glycoprotein. The extra methyl groups also confer on cabazitaxel the unique ability to cross the blood-brain 
barrier. In phase I trials, cabazitaxel at a dose of $25 \mathrm{mg} / \mathrm{m}^{2}$ was well tolerated; the most frequently reported adverse events were low-grade diarrhea (52\%), nausea (40\%) and vomiting $(16 \%)$. The dose-limiting toxicity was grade 4 neutropenia [41].

The Phase III trial (TROPIC) established the efficacy and safety of cabazitaxel in 755 patients with progressive mCRPC on or after being treated with docetaxel [8]. Patients received oral prednisone $10 \mathrm{mg}$ daily and were randomly assigned to receive either $12 \mathrm{mg} / \mathrm{m}^{2}$ mitoxantrone intravenously or $25 \mathrm{mg} / \mathrm{m}^{2}$ cabazitaxel intravenously every 3 weeks. Cabazitaxel-treated patients had a median OS of 15.1 versus 12.7 months in the mitoxantrone-treated patients (HR: $0.70 ; p<0.001$ ). Similarly, the median PFS, PSA response rate, median time to PSA progression, tumor response and time to tumor progression were all improved in the cabazitaxel arm [8]. However, pain control and time to pain progression were similar in the two treatment arms. The survival advantage was independent across tumor grade and duration of prior ADT. The most common toxicity associated with cabazitaxel was grade 3-4 neutropenia, which occurred in $82 \%$ of patients, while febrile neutropenia was documented in $8 \%$ of patients. The non-hematological toxicities included diarrhea, fatigue, asthenia and peripheral neuropathy. Based on these data, the FDA and EMA granted approval for cabazitaxel in mCRPC patients whose disease progresses during or after docetaxel treatment.

\section{Molecular determination of resistance to AR-directed therapies}

The choice of sequencing today depends on clinical factors at the discretion of the clinician. It is evident from trials that approximately one third of patients have primary resistance to AR-directed treatment. The only predictive factor for resistance is the prior duration of response to ADT, with chemotherapy the choice of treatment, if the ADT duration is less than 1 year. AR-directed therapy is not successful in patients with short duration of response to ADT, while Cabazitaxel is effective independent of the ADT duration.

We need biomarkers to lead the choice of sequencing therapies. One promising data concerns the use of AR splice variant AR-V7 to decide on the use of abiraterone or enzalutamide. AR, encoded by the splice variant 7 , does not carry the ligand-binding domain targeted by enzalutamide and abiraterone, but remains active as a transcription factor. A pilot trial testing the presence of $\mathrm{AR}-\mathrm{V} 7$ in the circulating tumor cells of 62 patients receiving enzalutamide or abiraterone and correlating this finding with response has shown that the presence of AR-V7 clearly indicates resistance to AR-directed therapy [42]. Figure 2 displays the correlation of PSA response to AR-V7 presence. Both PSA progression-free survival and clinical progression-free survival were significantly better in the AR-V7 negative patients.

Another preliminary study has found that the presence of AR-V7 does not influence response to chemotherapy. The value of AR-V7 as a predictor of hormone resistance remains to be prospectively tested in larger trials.

Table II. Summary of bone-targeting and bone metastasis-targeting agents that are approved in metastatic castration-resistant prostate cancer

\begin{tabular}{|c|c|c|c|c|c|c|}
\hline Treatment & Phase III trial & Indication & Sample size (n) & Control arm & Primary end point & Secondary end points \\
\hline $\begin{array}{l}\mathrm{Z} 4 \text { iv. or } \mathrm{Z8} \\
\text { iv. } \rightarrow 4 \mathrm{mg}\end{array}$ & $\begin{array}{c}\text { Zoledronic Acid } \\
\text { Prostate Cancer } \\
\text { Study }\end{array}$ & $\mathrm{mCRPC}$ & 643 & Placebo & $\begin{array}{l}\text { SRE rate }(Z 4 \text { vs } Z 8 \rightarrow 4 \\
\mathrm{mg} \text { vs } \mathrm{P}): 38 \text { vs } 41 \text { vs } 49 \% \\
(\mathrm{p}[\mathrm{Z} 4 \text { vs } \mathrm{P}]=0.028)\end{array}$ & $\begin{array}{l}\text { Time to first SRE ( } Z 4 \text { vs } Z 8 \rightarrow 4 \mathrm{mg} \\
\text { vs P): } 488 \text { vs } 363 \text { vs } 321 \text { days (HR [Z4 } \\
\text { vs P]: } 0.68 ; p=0.009) ; \text { mean annual } \\
\text { incidence of SREs ( } Z 4 \text { vs } Z 8 \rightarrow 4 \mathrm{mg} \\
\text { vs P): } 0.77 \text { vs } 1.05 \text { vs } 1.47(\mathrm{p} \text { [Z4 vs } \\
P)=0.005 \text { ); BPI (mean least squares } \\
\text { change from baseline value; } Z 4 \text { vs } Z 8 \\
\rightarrow 4 \mathrm{mg} \text { vs P): } 0.58 \text { vs } 0.54 \text { vs } 1.05 \text { (p } \\
(\mathrm{Z} 4 \text { vs P] }=0.024)\end{array}$ \\
\hline $\begin{array}{l}\text { Denosumab } \\
120 \mathrm{mg} \mathrm{sc} . \\
\mathrm{q} 4 \mathrm{w}\end{array}$ & $\begin{array}{c}\text { NCT } \\
00321620\end{array}$ & $\begin{array}{l}\text { mCRPC, } \\
\text { zoledronic } \\
\text { acid naive }\end{array}$ & 1904 & $\begin{array}{l}\text { Zoledronic } \\
\text { acid } 4 \mathrm{mg} \\
\text { q4w }\end{array}$ & $\begin{array}{l}\text { Time to first SRE: } 20.7 \text { vs } \\
17.1 \text { months (HR: } 0.82 \\
p=0.0002 \text { for nonin- } \\
\text { feriority; } p=0.008 \text { for } \\
\text { superiority) }\end{array}$ & $\begin{array}{l}\text { Time to first and subsequent SRE rate } \\
\text { ratio: } 0.82(p=0.008)\end{array}$ \\
\hline $\begin{array}{l}\text { Radium-223 } \\
50 \mathrm{kBq} / \mathrm{kg} \\
\mathrm{q} 4 \mathrm{w}\end{array}$ & ALSYMPCA & mCRPC & 921 & Placebo & $\begin{array}{l}\text { OS: } 14.9 \text { vs } 11.3 \text { months } \\
\text { (HR: } 0.70 ; \mathrm{p}<0.001 \text { ) }\end{array}$ & $\begin{array}{l}\text { Time to first SSE: } 15.6 \text { vs. } 9.8 \text { months } \\
\text { (HR: } 0.66 ; \mathrm{p}<0.001 \text { ); time to ALP } \\
\text { increase: } 7.4 \text { vs } 3.8 \text { months (HR: } 0.17 \text {; } \\
\text { p }<0.001 \text { ); time to PSA progression: } \\
3.6 \text { vs } 3.4 \text { months (HR: } 0.64 ; \mathrm{p}< \\
0.001 \text { ) }\end{array}$ \\
\hline
\end{tabular}

ALP: Alkaline phosphatase; BPI: Brief Pain Inventory; HR: Hazard ratio; iv.: Intravenous; mCRPC: Metastatic castration-resistant prostate cancer; P: Placebo; PSA: Prostate-specific antigen; q3w: Every 3 weeks; q4w: Every 4 weeks; sc.: Subcutaneous; SRE: Skeletal-related event; SSE: Symptomatic skeletal event; Z4: Zoledronic acid 4 mg every 3 weeks; Z8: Zoledronic acid 8 mg every 3 weeks. 

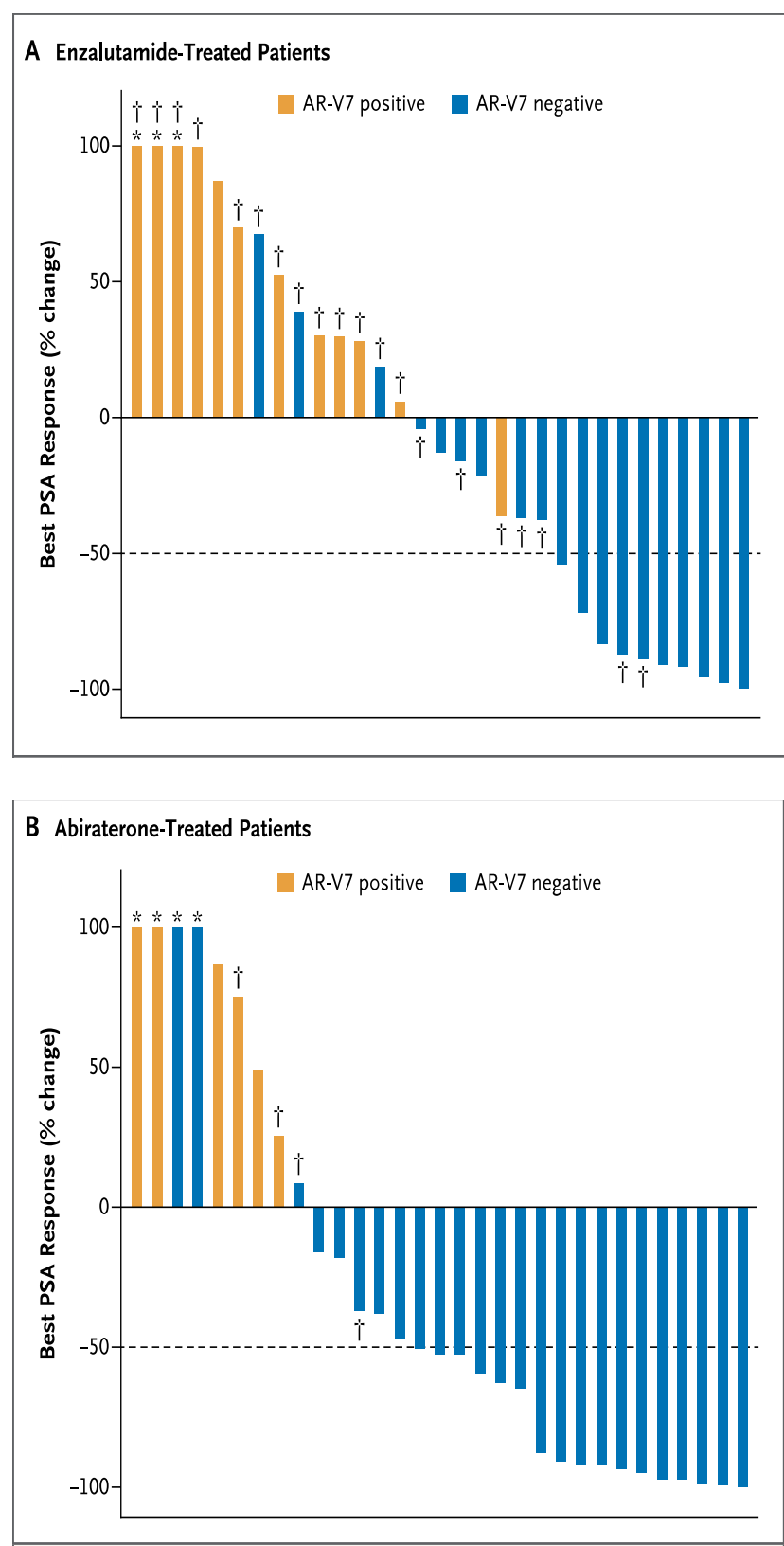

Figure 2. Correlation of PSA response to AR-V7 presence [42]

\section{BONE-TARGETING \& BONE METASTASIS- TARGETING AGENTS}

Metastatic cancer cells in the bone microenvironment release a number of cytokines and growth factors that induce an alteration of bone resorption/formation processes, resulting in lytic bone lesions, blastic bone lesions or both. Although metastatic bone lesions from prostate cancer are typically osteoblastic, osteolysis is also a common feature, caused by secondary hyperparathyroidism due to the so-called 'hungry bone syndrome' and by androgen deprivation-induced osteoporosis. Due to bone loss, CRPC patients with bone metastases commonly experience SREs. If the disease is androgen sensitive, SREs are rare. However, SREs become frequent in CRPC [43].

\section{Zoledronic Acid}

Zoledronic acid, a powerful third-generation nitrogencontaining bisphosphonate, was the first agent to be approved for the management of bone metastases in patients with CRPC (44). A Phase III placebo-controlled trial of zoledronic acid $4 \mathrm{mg}$ every 3 weeks versus placebo in 643 patients with mCRPC showed a reduced incidence of SREs; $44 \%$ of patients in the placebo group experienced a SRE compared with $33 \%$ in the experimental group $(\mathrm{p}=0.021)$. Zoledronic acid also significantly increased the time to first SRE (488 vs. 321 days; $p=0.009$ ). Pain scores and the use of analgesic drugs favored zoledronic acid, but there were no differences in either disease progression or OS [4].

\section{Denosumab}

The RANK/RANKL pathway plays a central role in bone resorption regulation. RANKL is part of the TNF family and is produced by osteoblasts. RANKL is able to bind RANK on the surface of both osteoclast precursors and osteoclasts, inducing osteoclast maturation, survival and activity [44]. Denosumab is a fully human monoclonal antibody against RANKL; preventing RANKL from activating its receptor, RANK, thus inhibiting osteoclast formation, function and survival, decreasing bone resorption and increasing bone mass and strength in both cortical and trabecular bone [9]. When compared with zoledronic acid in a Phase III trial that enrolled 1904 patients with mCRPC to the bone, denosumab at 120 mg every 28 days improved the median time to first SRE by 3.6 months (HR: $0.82 ; p=0.008$ ). The two groups had similar OS and time to disease progression. Adverse event rates were also similar, with the exception of an increased incidence of hypocalcemia $(13 \%$ in the denosumab group vs. $6 \%$ in the zoledronic acid group; $\mathrm{p}<0.0001)$. Denosumab has been approved by the FDA and EMA for the treatment of mCRPC patients with bone metastases.

\section{Radium-223 Dichloride}

Radium-223 is a targeted $\alpha$-emitter that acts as calcium mimetic and selectively binds areas of new bone growth in and around bone metastases. Unlike $\beta$-emitting agents that are myelotoxic, radium-233 emits ionizing radiation with high energy and extremely short penetration $(<100 \mu \mathrm{m}$; 2-10 cell diameters), causing highly localized tumor cell killing with minimal side effects to normal cells [45].

The FDA and EMA recently approved radium-223 for the treatment of patients with CRPC and symptomatic bone metastases on the basis of the results of the ALSYMPCA trial [12]. This Phase III placebo-controlled trial assessed 
the efficacy and safety of radium-223 in patients with CRPC and symptomatic bone metastases pretreated with or unfit for docetaxel. The primary end point was OS; secondary end points included time to first SSE, time to an increase in alkaline phosphatase or PSA levels and safety. 921 patients were randomized with an allocation ratio of 2:1 to receive radium-223 at a dose of $50 \mathrm{kBq} / \mathrm{Kg}$ administered as six injections at 4-weekly intervals or placebo. Radium-223 was well tolerated and significantly improved OS by $30 \%$ (14.9 versus 11.3 months; HR: 0.70 ; $95 \%$ CI: $0.58-0.83 ; \mathrm{p}<$ 0.001 ) and delayed time to first SSE [12].

\section{IMMUNOTHERAPY}

Prostate cancer is an attractive target for therapeutic cancer vaccines because it expresses a number of tumor-associated antigens and exhibits slow growth, which could allow the immune system to have sufficient time to induce an effective antitumor immune response. In addition, disease recurrence is often diagnosed early (with many patients only having biochemical progression) and there is a biological marker that is able to detect early relapse (PSA and PSA doubling time) [46].

\section{Sipuleucel-T}

Sipuleucel-T is a cellular immunotherapy aimed at stimulating an immune response against a widely expressed prostate cancer antigen, prostatic acid phosphatase, fused with GM-CSF. Efficacy of sipuleucel-T was demonstrated in three randomized, double blind, controlled, multicenter Phase III studies (D9901, D9902A and D9902B) that enrolled a total of 737 patients. An integrated analysis of two of the studies - D9901 and D9902A- showed that sipuleucel-T provided OS benefit compared with placebo (23.2 vs. 18.9 months; $p=0.011$ ) [47].

The IMPACT study (D9902B) included patients with asymptomatic or minimally symptomatic chemotherapynaive mCRPC, predominantly with rising PSA (7). 512 patients were randomized to sipuleucel- $\mathrm{T}(\mathrm{n}=341)$ versus placebo $(\mathrm{n}=171)$ in a $2: 1$ ratio. The primary end point was met, with a median OS improvement for the experimental arm of 4.1 months (25.8 vs. 21.7 months; $\mathrm{p}=0.03$ ). However, there was no significant effect on PSA response rate, radiologic responses or time to progression. SipuleucelT-related toxicities were mainly infusion-related chills, nausea, fever, headache and fatigue. This trial led to FDA approval for the treatment of asymptomatic or minimally symptomatic mCRPC, but treatment costs and complicated reimbursement strategies have limited its use.

\section{PROSTVAC®-VF}

PROSTVAC ${ }^{\circledR}-\mathrm{VF}$ (Bavarian Nordic, Kvistgaard, Denmark) is a recombinant vaccine consisting of two vectors encoding
PSA and three immune co-stimulatory agents, administered with a fowlpox viral boost. In a Phase II, randomized, double blind, placebo-controlled trial, 125 patients with minimally symptomatic mCRPC were randomized 2:1 to PROSTVACVF or control empty vectors. Patients randomized to the immunotherapy received a priming dose of PROSTVAC-V, followed by six booster doses administered with low-dose GM-CSF. The primary end point was PFS, which was similar in the two groups $(\mathrm{p}=0.6)$. However, median OS in the immunotherapy-treated group was improved (25.1 vs. 16.6 months; HR: 0.56; $\mathrm{p}=0.0061$ ) [48].

PROSTVAC-VF is currently being tested in a Phase III trial (NCT01322490) in which patients are randomized to three treatment groups: PROSTVAC-VF, vaccine plus GMCSF or vector placebo control. The primary end point of this study is OS and it is statistically powered to detect $18 \%$ differences in the HRs for all between-group comparisons.

\section{Ipilimumab}

Ipilimumab is a human monoclonal antibody that enhances and prolongs $\mathrm{T}$-cell activation by blocking immune checkpoint CTLA-4 receptors found on the surface of T cells. In a randomized Phase II trial, 108 patients with advanced prostate cancer treated with ipilimumab plus androgendeprivation therapy were more likely to have undetectable PSA levels by 3 months compared with those treated with endocrine therapy alone ( 55 vs. $38 \%$ ). Ipilimumab has been tested against placebo with radiation treatment [49], and also following bone-directed radiation therapy in patients with CRPC previously treated with docetaxel [50]. These studies did not meet their endpoints of OS. Prespecified subset analyses suggest that ipilimumab may be most active in patients with favorable laboratory prognostic factors (e.g., decreased alkaline phosphatase or elevated hemoglobin level) or in patients without visceral disease.

\section{SEQUENCING \& COMBINATIONS}

We are thankful for the appearance of many effective therapeutic strategies in CRPC, but now are faced with the challenge of sequencing treatments in each individual patient. There is even less data for combination of these therapeutic approaches. Factors to be considered in decisionmaking are the patient's clinical status (e.g., asymptomatic or symptomatic), rate of disease progression and disease burden, presence of bone or visceral metastases, mechanism of action, tolerability and side effects, prior treatments and response.

For docetaxel-untreated patients, abiraterone and enzalutamide both represents valid therapeutic options for asymptomatic or minimally symptomatic mCRPC patients without visceral disease. Since AR-directed therapy is effective before docetaxel, the next question is whether 
subsequent docetaxel efficacy may be reduced. Preclinical and clinical data suggest a partial cross-resistance between taxanes and AR-directed agents, possibly due to the effect of taxanes on the AR pathway. Prostatic carcinoma cells after CYP17 inhibitor treatment could undergo biological changes and become chemotherapy resistant due to crossresistance between AR-directed drugs and taxanes [51]. A small study demonstrated lower docetaxel activity in abiraterone-refractory patients [52]. Recently, Schweizer et al. retrospectively explored the efficacy of docetaxel after abiraterone treatment in 119 CRPC patients [53]. Patients who received abiraterone before docetaxel chemotherapy had worse PSA responses ( 38 vs. $63 \%$; $p=0.02$ ), shorter median PSA PFS (4.1 vs. 6.7 months; $p=0.002$ ) and worse median PFS (4.4 vs. 7.6 months; $p=0.003$ ). Multivariable analysis showed that prior abiraterone treatment was an independent predictor of shorter PSA PFS (HR: 3.48; 95\% CI: $1.36-8.94 ; \mathrm{p}=0.01$ ) and PFS (HR: 3.62 ; $95 \% \mathrm{CI}: 1.41-$ 9.27; $\mathrm{p}=0.008)[52]$.

Sipuleucel-T seems to be a valid option for carefully selected patients with asymptomatic disease, but loses its feasibility through cost and availability issues.

Docetaxel is the treatment of choice for patients with visceral metastases from $\mathrm{mCRPC}$ and symptomatic mCRPC in the chemotherapy-naive setting. Docetaxel also represents the first treatment choice for patients with asymptomatic disease but a rapid PSA doubling time. It is effective in both patients with symptomatic disease and those with asymptomatic disease.

For patients who have been pretreated with docetaxel, there are currently three therapeutic options: cabazitaxel, abiraterone and enzalutamide. All these three drugs have been demonstrated to be successful in improving OS after docetaxel failure. Nevertheless, no prospective study has compared the three therapeutic options yet, and the clinical utility of markers of hormone resistance such as AR splice variant 7 remains to be seen. A retrospective analysis based on data collected from several clinical trials of second-line hormonal therapy in patients with CRPC indicated that a longer-lasting response to previous hormonal treatment is a positive predictive factor for a response to either abiraterone, ketoconazole-hydrocortisone, bicalutamide or estrogens. Another retrospective study identified predictive factors for treatment response; patients who already underwent two or more lines of chemotherapy or those with a high Gleason score had less chance of being responsive to abiraterone. According to these data, it is reasonable to hypothesize that patients with a well-differentiated tumor, and especially those with a longer-lasting response to first-line hormonal therapy, have better results with new-generation endocrine agents.

The use of AR-directed therapies in earlier phases of treatment, or the combination of abiraterone and enzalutamide are being tested in larger trials. Attempts are made to increase the efficacy of docetaxel through combination with other agents such as antiVEGF molecules, vitamin $\mathrm{D}$, lenalinomide, and endothelin antagonists, all of which failed to show survival benefit. One very interesting trial is comparing cabazitaxel $25 \mathrm{mg} / \mathrm{m}^{2}$ versus cabazitaxel $20 \mathrm{mg} / \mathrm{m}^{2}$ versus standard first-line docetaxel chemotherapy (FIRSTANA; NCT01308567).

A better understanding of new drug resistance mechanisms and prostate cancer molecular subtypes based on genomic and proteomic analysis, as well as prognostic and predictive biomarkers, may further improve mCRPC treatment. Future efforts have to be made in order to tie prostate cancer biology to therapy so as to maximize benefit and minimize toxicity and costs.

\section{References}

1. Damber JE. Endocrine therapy for prostate cancer. Acto Oncol 2005; 44: 605-9.

2. Scher HI, Halabi S, Tannock I, et al. Design and end points of clinical trials for patients with progressive prostate cancer and castrate levels of testosterone: recommendations of the Prostate Cancer Clinical Trials Working Group. J Clin Oncol 2008; 26:1148-59. doi: 10.1200/JCO.2007.12.4487.

3. Kirby M, Hirst C, Crawford ED. Characterising the castration-resistant prostate cancer population: a systematic review. Int J Clin Pract 2011; 65; 1180-92. doi: 10.1111/j.1742-1241.2011.02799.x.

4. Saad F, Gleason DM, Murray R, et al. A randomized, placebo-controlled trial of zoledronic acid in patients with hormone-refractory metastatic prostate carcinoma. J Natl Cancer Inst 2002; 94: 1458-68. 5. Tannock IF, de Wit R, Berry WR, et al. Docetaxel plus prednisone or mitoxantrone plus prednisone for advanced prostate cancer. N Engl J Med 2004; 351: 1502-12.

6. Petrylak DP, Tangen CM, Hussain MH, et al. Docetaxel and estra-mustine compared with mitoxantrone and prednisone for advanced refractory prostate cancer. $\mathrm{N}$ Engl J Med 2004; 351: 1513-20.

7. Kantoff PW, Higano CS, Shore ND, et al. Sipuleucel-T immunotherapy for castration-resistant prostate cancer. N Engl J Med 2010; 36:, 411-22. doi: 10.1056/ NEJMoa1001294.

8. de Bono JS, Oudard S, Ozguroglu M, et al. Prednisone plus cabazitaxel or mitoxantrone for metastatic castrationresistant prostate cancer progressing after docetaxel treatment: a randomised open-label trial. Lancet 2010; 376: 1147-54. doi: 10.1016/S0140-6736(10)61389-X

9. Fizazi K, Carducci M, Smith M, et al. Denosumab versus zoledronic acid for treatment of bone metastases in men with castration-resistant prostate cancer: a randomised, double-blind study. Lancet 2011; 377(9768): 813-22. doi: 


\subsection{6/S0140-6736(10)62344-6.}

10. de Bono JS, Logothetis CJ, Molina A, et al. Abiraterone and increased survival in metastatic prostate cancer. N Engl J Med 2011; 364: 1995-2005. doi: 10.1056/ NEJMoa1014618.

11. Scher HI, Fizazi K, Saad F, et al. Increased survival with enzalutamide in prostate cancer after chemotherapy. NEngl J Med 2012; 367: 1187-97. doi: 10.1056/NEJMoa1207506 12. Parker C, Nilsson S, Heinrich D, et al. Alpha emitter radium-223 and survival in metastatic prostate cancer. N Engl J Med 2013; 369: 213-23. doi: 10.1056/ NEJMoa1213755.

13. Huggins C. Effect of orchiectomy and irradiation on cancer of the prostate. Ann Surg 1942; 115: 1192-200.

14. Mohler Jl. Castration-recurrent prostate cancer is not androgen independent. Adv Exp Med Biol 2008;617: 223-34.

15. Debes JD, Tindall DJ. Mechanisms of androgen-refractory prostate cancer. N Engl J Med N 2004; 351: 1488-90. doi: 10.1056/NEJMp048178

16. Hu R, Dunn TA, Wei S, et al. Ligand-independent androgen receptor variants derived from splicing of cryptic exons signify hormone-refractory prostate cancer. Cancer Res 2009; 69: 16-22. doi: 10.1158/0008-5472.CAN-08-2764.

17. Stanbrough M, Bubley GJ, Ross K, et al. Increased expression of genes converting adrenal androgens to testosterone in androgen-independent prostate cancer. Cancer Res 2006; 66: 2815-25.

18. Holzbeierlein J, Lal P, LaTulippe E, et al. Gene expression analysis of human prostate carcinoma during hormonal therapy identifies androgen-responsive genes and mechanisms of therapy resistance. Am J Pathol 2004; 164 : 217-27.

19. Sonpavde G, Attard G, Bellmunt J, et al. The role of abiraterone acetate in the management of prostate cancer: a critical analysis of the literature. Eur Urol 2011; 60: 2708. doi: 10.1016/j.eururo.2011.04.032.

20. Attard G, Reid AH, Auchus RJ, et al. Clinical and biochemical consequences of CYP17A1 inhibition with abiraterone given with and without exogenous glucocorticoids in castrate men with advanced prostate cancer. J Clin Endocrinol Metab 2012; 97: 507-16. doi: 10.1210/jc.2011-2189.

21. Pia A, Vignani F, Attard G, et al. Strategies for managing ACTH dependent mineralocorticoid excess induced by abiraterone. Cancer Treat Rev 2013; 39: 966-73. doi: 10.1016/j.ctrv.2013.03.003.

22. Fizazi K, Scher HI, Molina A, et al. Abiraterone acetate for treatment of metastatic castration-resistant prostate cancer: final overall survival analysis of the COU-AA-301 randomised, double-blind, placebo-controlled Phase 3 study. Lancet Oncol 2012; 13: 983-92. doi: 10.1016/ S1470-2045(12)70379-0.

23. Ryan CJ, Smith MR, de Bono JS et al. Abiraterone in metastatic prostate cancer without previous chemotherapy.N Engl J Med 2013; 368: 138-48. doi: 10.1056/NEJMoa1209096.

24. RathkopfDE, Smith RE, de Bono JS, et al. Updated interim efficacy analysis and long-term safety of abiraterone acetate in metastatic castration-resistant prostate cancer patients without prior chemotherapy (COU-AA-302). Eur Urol 2014; 66:815-25. doi: 10.1016/j.eururo.2014.02.056.

25. Dreicer R, Maclean D, Suri A, et al. Phase 1/2 trial of orteronel (TAK-700) - an investigational 17,20-lyase inhibitor - in patients with metastatic castration-resistant prostate cancer. Clin Cancer Res 2014; 20: 1335-44. doi: 10.1158/1078-0432.CCR-13-2436.

26. Dreicer R, Jones R, Oudard S, et al. Results from a Phase 3, randomized, double-blind, multicenter, placebocontrolled trial of orteronel (TAK-700) plus prednisone in patients with metastatic castration-resistant prostate cancer (mCRPC) that has progressed during or following docetaxel-based therapy (ELM-PC 5 trial). J Clin Oncol 2014;32(suppl 4):7.

27. De Wit R FK, Jinga V, Efstathiou E, et al. Phase 3, randomized, placebo-controlled trial of orteronel (TAK700) plus prednisone in patients with chemotherapy-naive metastatic castration-resistant prostate cancer (mCRPC) (ELM-PC4 trial). J Clin Oncol 2014;32(suppl 5):5008.

28. Scher HI, Beer TM, Higano CS, Anand A, Taplin ME, Efstathiou E, Rathkopf D, Shelkey J, Yu EY, Alumkal J, Hung D, Hirmand M, Seely L, Morris MJ, Danila DC, Humm J, Larson S, Fleisher M, Sawyers CL, Prostate Cancer Foundation/Department of Defense Prostate Cancer Clinical Trials Consortium: Antitumour activity of MDV3100 in castration-resistant prostate cancer: a phase 1-2 study. Lancet 2010, 375(9724):1437-46. doi: 10.1016/S0140-6736(10)60172-9.

30. Scher HI, Fizazi K, Saad F, Taplin ME, Sternberg CN, Miller K, de Wit R, Mulders P, Chi KN, Shore ND, Armstrong AJ, Flaig TW, Fléchon A, Mainwaring P, Fleming M, Hainsworth JD, Hirmand M, Selby B, Seely L, de Bono JS, AFFIRM Investigators: Increased survival with enzalutamide in prostate cancer after chemotherapy.N EngL J Med 2012, 367:1187-97. doi: 10.1056/NEJMoa1207506

31. Beer TM, Armstrong AJ, Sternberg CN, Higano CS, Iversen P, Loriot Y, Rathkopf DE, Bhattacharya S, Carles J, De Bono JS, Evans CP, Joshua AM, Kim C-S, Kimura G, Mainwaring PN, Mansbach HH, Miller K, Noonberg SB, Venner PM, Tombal B: Enzalutamide in men with chemotherapy-naive metastatic prostate cancer (mCRPC): Results of phase III PREVAIL study. J Clin Oncol 2014, 32(4 Suppl):LBA1. 
32. Vasaitis T, Belosay A, Schayowitz A, et al. Androgen receptor inactivation contributes to antitumor efficacy of 17 alpha\}-hydroxylase/17,20-lyase inhibitor 3betahydroxy-17-(1H-benzimidazole-1-yl)androsta-5,16-diene in prostate cancer. Mol Cancer Ther 2008; 7:2348-57. doi: 10.1158/1535-7163.MCT-08-0230.

33. Taplin M, Chu F, Morrison J, et al. ARMOR1: safety of galeterone (TOK-001) in a phase 1 clinical trial in chemotherapy naïve patients with castration resistant prostate cancer (CRPC). Cancer Res 2012; 72(8 Supplement):CT-07.

34. Taplin ME, Montgomery RB, ARMOR2 Group. ARMOR2: galeterone in progressive CRPC patients who have failed oral therapy. Presented at: 2014 Genitourinary Cancers Symposium. San Francisco, CA, USA, 29 January-2 February 2014.

35. Clegg NJ, Wongvipat J, Joseph JD, Tran C, Ouk S, Dilhas A, Chen Y, Grillot K, Bischoff ED, Cai L, Aparicio A, Dorow S, Arora V, Shao G, Qian J, Zhao H, Yang G, Cao C, Sensintaffar J, Wasielewska T, Herbert MR, Bonnefous C, Darimont B, Scher HI, Smith-Jones P, Klang M, Smith ND, De Stanchina E, Wu N, Ouerfelli O, et al.: ARN-509: a novel antiandrogen for prostate cancer treatment. Cancer Res 2012, 72:1494-1503. doi: 10.1158/0008-5472.CAN$11-3948$

36. Smith MR. ARN-509 in men with high-risk nonmetastatic castration-resistant prostate cancer (CRPC). J Clin Oncol 2013; 31(6 Suppl):7.

37. Berthold DR, Pond GR, Soban F, de Wit R, Eisenberger M, Tannock IF. Docetaxel plus prednisone or mitoxantrone plus prednisone for advanced prostate cancer: updated survival in the TAX 327 study. J Clin Oncol 2008; 26: 242-5. doi: 10.1200/JCO.2007.12.4008

38. Di Lorenzo G, Buonerba C, Faiella A, et al. Phase II study of docetaxel re-treatment in docetaxel-pretreated castration-resistant prostate cancer. BJU Int 2011; 107: 234-9. doi: 10.1111/j.1464-410X.2010.09498.x.

39. Sweeney CJ. Insights into E3805: the CHAARTED trial. Future Oncol 2015; 11: 897-9. doi: 10.2217/fon.14.310.

40. Bouchet BP, Galmarini CM. Cabazitaxel. A new taxane with favorable properties. Drugs Today (Barc.) 2010; 46: 735-42. doi: 10.1358/dot.2010.46.10.1519019.

41. Mita AC, Denis LJ, Rowinsky EK, et al. Phase I and pharmacokinetic study of XRP6258 (RPR 116258A), a novel taxane, administered as a 1-hour infusion every 3 weeks in patients with advanced solid tumors. Clin Cancer Res 2009; 15: 723-30. doi: 10.1158/1078-0432.CCR-080596.

42. Antonarakis ES, Lu C, Wang H, et al. AR-V7 and resistance to enzalutamide and abiraterone in prostate cancer. N Engl J Med 2014;371:1028-38. doi: 10.1056/ NEJMoa1315815.
43. Tucci M, Mosca A, Lamanna G et al. Prognostic significance of disordered calcium metabolism in hormone-refractory prostate cancer patients with metastatic bone disease. Prostate Cancer Prostatic Dis 2009; 12: 94-9. doi: 10.1038/pcan.2008.10.

44. Baron R, Ferrari S, Russell RGG. Denosumab and bisphosphonates: different mechanisms of action and effects. Bone 2011; 48: 677-92. doi: 10.1016/j. bone.2010.11.020.

45. Pinto A, Cruz P. Radium-223 chloride. A new treatment option for metastatic castration-resistant prostate carcinoma. Drugs RD 2013;12: 227-33. doi: 10.2165/11636250-000000000-00000.

46. Joniau S, Abrahamsson PA, Bellmunt J, et al. Current vaccination strategies for prostate cancer. Eur Urol 2012; 61: 290-306. doi: 10.1016/j.eururo.2011.09.020.

47. Higano CS, Schellhammer PF, Small EJ et al. Integrated data from 2 randomized, double-blind, placebo-controlled, Phase 3 trials of active cellular immunotherapy with sipuleucel-T in advanced prostate cancer. Cancer 2009; 115: 3670-9. doi: 10.1002/cncr.24429.

48. Kantoff PW, Schuetz TJ, Blumenstein BA, et al. Overall survival analysis of a Phase II randomized controlled trial of a poxviral-based PSA-targeted immunotherapy in metastatic castration resistant prostate cancer. J Clin Oncol 2010; 28: 1099-105. doi: 10.1200/JCO.2009.25.0597.

49. Slovin SF, Higano CS, Hamid O, et al. Ipilimumab alone or in combination with radiotherapy in metastatic castration-resistant prostate cancer: results from an openlabel, multicenter Phase I/II study. Ann Oncol 2013; 24: 1813-21. doi: 10.1093/annonc/mdt107.

50. Kwon ED, Drake CG, Scher HI, et al. Ipilimumab versus placebo after radiotherapy in patients with metastatic castration-resistant prostate cancer that had progressed after docetaxel chemotherapy (CA184-043): a multicenter, randomized, double blind, Phase 3 trial. Lancet Oncol 2014; 15: 700-12. doi: 10.1016/S1470-2045(14)70189-5.

51. van Soest RJ, van Royen ME, de Morree ES , et al. Crossresistance between taxanes and new hormonal agents abiraterone and enzalutamide may affect drug sequence choices in metastatic castration-resistant prostate cancer. Eur J Cancer 2013; 49: 3821-30. doi: 10.1016/j. ejca.2013.09.026.

52. Mezynski J, Pezaro C, Bianchini D, et al. Antitumour activity of docetaxel following treatment with the CYP17A1 inhibitor abiraterone: clinical evidence for cross-resistance? Ann Oncol 2012; 23: 2943-7. doi: 10.1093/annonc/mds119.

53. Schweizer MT, Zhou XC, Wang H, et al. The influence of prior abiraterone treatment on the clinical activity of docetaxel in men with metastatic castration-resistant prostate cancer. Eur Urol 2014; 66: 646-52. doi: 10.1016/j. eururo.2014.01.018. 